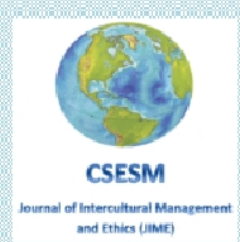

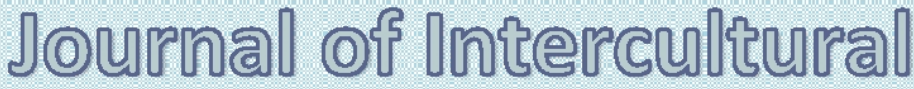

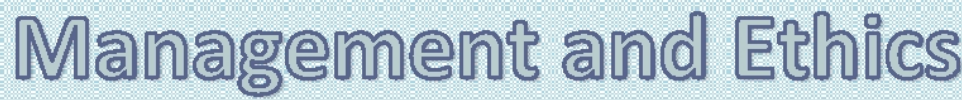

\author{
I0ME
}

ISSN 2601 - 5749, ISSN-L 2601 - 5749

Center for Socio-Economic Studies and Multiculturalism

lasi, Romania

WWW csesmioirg 


\section{TABLE OF CONTENT}

Editorial

Iulian Warter

Where Did Culture Come From? Evolutionary Foundations of Cultural Diversity

Paulo Finuras

Crash: Boeing and the Power of Culture

Thomas D. Zweifel, Vip Vyas

Political Culture, Social Polarization and Electoral Behavior. The Last Decade in Romanian

Political System

Silviu-Petru Grecu

The Principles of Transparency and Judging Others Favorably: The Talmudic View

Hershey H. Friedman, Robert B. Fireworker

Some Issues Regarding the Ethics of the Management at Romanian State-Owned

Companies .55

Baluta Aurelian Virgil, Rada Alexandru Cristian

How Does Logistics Command of the Military Navy Support Local Development and

Cultural Integration?

Rosa Caiazza

Illusion and Disillusion. Case Studies about the Constitution of a New Political Party in

Romania

Alexandru Muraru

How Could We Overcome the Feeling Of Insecurity? Explorations in the Spectrum of Polyscopic Consciousness

Anton Carpinschi

The Employees' Perceptions, Practices and Experiences Regarding the Strategic Process

Carried Out In the Public Hospitals

Ana Niculita 


\title{
WHERE DID CULTURE COME FROM? EVOLUTIONARY FOUNDATIONS OF CULTURAL DIVERSITY
}

\author{
Paulo Finuras, Ph.D. \\ Associate Professor of Organisational Behavior \\ ISG - Lisbon Business \& Economics School, Portugal \\ E-mail: paulo.finuras@isg.pt
}

\begin{abstract}
The existence of different cultures remains a puzzle in our evolutionary history. There is, apparently, a process of "downward causation", in the sense that (national) cultures are collective facts and mental programs outside the individuals and influence them from top to bottom.

Here I propose that human societies and cultures, as a whole, end up fulfilling the basic requirements of biological evolution, producing variation for diversity, selection for the retention of solutions and stability for the transmission of collective options throughout time and between social groups of such diverse magnitude and scale that they range from a few thousand to more than a billion individuals. This is something that occurs in all human societies. In sum, we claim that cultural variations are the result of various adaptive responses of phenotypes in their bio-economic optimization of permanent pressures of various environments and local conditions.
\end{abstract}

Keywords: Culture, diversity, evolutionary psychological mechanisms, human evolution

\section{Introduction ${ }^{1}$}

Enough attention has been given to research on cultural differences and their consequences to "collective behaviours", and less attention has been put to the foundational explanation regarding the origin of culture and cultural variations.

Generally speaking, people are the same everywhere, but cultures are not because culture is a collective behaviour. So, before we talk about cultural differences and culture as an "information system", it might be worth reflecting on the origin and evolution of culture.

Our species is highly altricial where human beings are born with a "program opening" (Mayr, 1974). Unlike other species of mammals and primates, we are born completely helpless, deprived and without autonomy, requiring extensive and deep care and attention from the parents, first and group, secondly and it is probably what is at the basis of our "tribal instinct".

We must consider that our brain swelled three-fold before it began to shrink in size 5,000 years ago, according to estimates, converging with the time when human civilizations began to flourish and with them collective and external knowledge to the individual. In fact, the rise of our brain driven by the ability of language had to stop at some point in our history, which is understandable. If, on the one hand, we needed larger brains, on the other hand, this created a fetus-pelvic conflict threatening the woman at birth, which still makes human childbirth dangerous, although, in the present times, this is greatly mitigated by the development of obstetric technology. The way that nature found to solve this conflict was

\footnotetext{
${ }^{1}$ This article is a summary with modifications introduced from a chapter of my book Human Affairs - Evolution \& Behavior (2021).Lisbon: Edições Sílabo
} 
anticipating pregnancy for the average nine months of gestation, making it possible that when the human being is born is nothing more than an extra uterine fetus, totally vulnerable and dependent on the parents and the immediate group. Under these conditions, the behavioral repertoire of inborn program is reduced in the inverse proportion of the sum of the learned behaviors (Vieira, 2015). And we must ask: learned from where? The answer is: from culture. Human cubs are beings wide and dominantly open to culture becoming this a sine qua non condition for human development. It is through the acquired culture that several of the programmed instilled behaviors retreat, giving rise to cultural practices and behaviors.

But if at the individual level and the evolution of the species this responds to some adaptive pressures, another question arises at the level of human groups: what gave rise to "human culture(s)"?

\section{The emergence of Culture}

Several factors have contributed to the possibility of selection of this strategy by evolution and the emergence of our "capacity for culture". The debate between the innate and acquired (nurture vs nature) is more than wrong because it is deeply misplaced. There is no dichotomy between nature and nurture because the second is part of the first. It is our nature that allows us to acquire culture, without which we do not develop or become humans.

The sequence of events that gave rise to "human culture" and cultural differences, something that now we can consider mostly national or ethnic cultures, involves many and interrelated causal mechanisms. Any attempt to describe culture in a completely way will necessarily be an excessive simplification of the process. Nevertheless, some research has been produced which help us better understand how natural selection has shaped our abilities to produce culture.

If seems true that selective forces have shaped our capabilities for culture, is also true that, in turn, culture gave rise to new selective forces that further shaped our ancestors in a cascading process that favoured the complexity of culture as a collective phenomenon. If the process of the emergence of culture in human communities has become irreversible, it is because, for evolution, the benefits outweigh the costs and, as we know, nature tends to fix and develop the strategies that have proved effective in our past. This is the criterion that nature seems to use to arbitrate any conflict or reward the adaptive solutions that endure. That is why, in our opinion, there is no nature versus creation. The acquired is part of our innate. Culture is part of our nature!

The human capacity for cooperation is critical to the emergence and development of culture among humans. The cultural information system has allowed us to solve two of our main and central problems: trust and social coordination! Therefore, the ability for cooperation in the way that it occurs between human beings was one of the main triggers towards the construction of human culture - and this is a product of evolution. Culture came from inside out. It is a bottom-up process. There is no-one in charge. In summary, culture is an evolutionary phenomenon. For all this, culture is a collective phenomenon and not an individual one.

There are no doubts that culture has its origins in the individual behaviours and cognitions, but it is more than that. It is a "macro manifestation" of our nature and biology which characterizes humankind.

\section{The diversification of cultures}

In the last tens of thousands of years, human cultures have diversified in a similar way to groups of species in the natural world, but more quickly. It is this "gap" between the speeds with which our cultural environment has changed in comparison to our "mental 
equipment" that generates many situations of incompatibility, mismatch, or maladjusted behaviours (Van Vugt et al., 2008; Van Vugt \& Ahuja, 2010; Nesse, 2019).

In sum, the central idea is that evolved mechanisms exist in the forms that they do because they led, on average, to our success during the period in which they evolved. That is, in the adaptive ancestral environment.

Like many others social scientists (Alexander, 1979; Barkow, 2005; Dawkins, 1976; Messoudi, 2011; Richerson \& Boyd, 2006; Tooby et al., 2006; Van Vugt, 2008), I also consider culture as a biological adaptation of the human race with Darwinian properties because cultures are also subject to the same "evolutionary algorithm": variation, selection and transmission: that is why culture evolves.

Diversity of, and within, human societies, generates and ensures the basic requirements for the evolution of humankind and this same diversity is the result of different collective responses to common problems. We can conclude that there is a common denominator to all human societies that is simultaneously the basis of their own differentiation. This is the anthropological "equivalent" of the biological principle of "invariant variance": what does not vary in cultures and human societies is the fact that all cultures and societies vary.

I must clarify that, in my opinion, "culture" and "society" are mutually dependent because, as functional units, none of them can exist without the other. On the one hand, without a common information system, society has a psychological identity that enables its members to be able to coordinate in order to live and work together. On the other hand, through human individual and collective action, society can provide and express a culture demonstration that spreads through horizontal replication and vertically transfers to succeeding generations. Human society is an organization of individuals who can cooperate and coordinate in order to survive and reproduce; culture is a social information system that organizes ideas and memes that feed on individuals who create, replicate, and even die for them.

Today, evolutionary anthropology and psychology assume that all cultural systems seem to be related by descent. It is suggested that probably a long and unbroken chain of cultural transmission connects all existing cultural and human communities through a single ancestor and, for however remote this original bond is, all cultures descended (by modification) from the original culture: all human societies were probably descendent from a "prime horde". It is a fact that the evolutionary cultural theory cannot provide definitive answers to several important issues, such as those relating to the cultural diversity, and is not able to explain why there are so many different cultures, and, for the same reason, why are not there more? $?^{2}$

As we know, natural selection works based on regularities. When these are successful and become relevant to the resolution of the major human problems, such as survival, reproduction, and co-ordination, those strategies are rewarded and merged as adaptive by evolution. Therefore, the roots of "how we are and what we do" must be, first, in biology. I suggest that there is a complementarity between evolutionary psychology and cultural diversity

\section{The cultural nature of human behaviour}

We can understand and better explain the "cultural nature of human behaviour" (regardless of the place where it occurs) if we understand culture as a result of simultaneous

\footnotetext{
2 The same occurs for the evolution of cultures: will they turn and change, first, into a gradual, and cumulative way or will it be through a large breakthrough of fast and punctuated transition? And how is this "fast" compared with current human societies' scales? What are the most important forces of change or cultural transformation? And in what way(s)?
} 
"aggregation and integration" of algorithms produced and shaped by our evolutionary history through inherited and learning memes and practices, which are acquired by horizontal and vertical replication.

If we look carefully at the set of human societies and cultures as a whole, we cannot ignore that they end up fulfilling the basic requirements of biological evolution, producing variation for diversity, selection for the retention of solutions and stability for the transmission of collective options throughout time and between social groups of such diverse magnitude and scale that they range from a few thousand to more than a billion individuals. This is something that occurs in all human societies and "in" human society and culture understood as a whole, that is, as one among the almost nine million species of living beings that we calculate exist on our planet ${ }^{3}$.

\section{Culture Variations}

In sum, cultural variations are the result of various adaptive responses of phenotypes in their bio-economic optimization of permanent pressures of various environments and local conditions (Barkow et al., 1992; Barkow, 2005). The following scheme summarizes all these ideas and the foundations of culture's "bottom-up" process (emergent properties) 4 .

In a nutshell, "cultural" phenomena possess three main key features, namely:

1) It is information that individuals acquire through learning, imitation, association and other forms of social learning, and that information is a "system of action, thought and emotion";

2) Culture is part of human biology. We, are, in ourselves, an evolutionary program that was born with a particular "opening", which hardwires us to acquire culture, without which we cannot develop as human beings;

3) All that we learn, think, remember and feel is shaped by the architecture of our mind and the evolutionary psychological mechanisms (EPM) that support it. There is no conflict between nature and nurture because we are, by nature, programmed to acquire culture.

Most human societies today are practically all nation-states. That is why we can talk about "national cultures" as Geert Hofstede put it ( see Hofstede, 1980, 2001, Hofstede et al., 2010).

In my view, Hofstede's approach is what I call a "culturetic" approach based on the comparative analysis of "human universals".(see Brown, 1991) The original designation is "emic versus etic approach"; however, I preferred to create the neologisms "culturetic" and "culturemic" from the original terms 5 .

The Hofstede dimensional model captures the common human problems, in the line of other great social scientists in the sixties of the last century (Kluckhohn \& Strodbeck, 1961). Based on the Hofstede model I would like to emphasize my own analysis of the four

\footnotetext{
${ }^{3}$ It is estimated that there are 8.7 million species on the planet, most of which are terrestrial (6.5 million and 2.2 million aquatic).

${ }^{4}$ It is true that cultural diversity offers obstacles but also unique opportunities for any evolutionary approach. I believe that any culture has psychological foundations in the first place, and these foundations are, in turn, supported by biological foundations. We should probably bear that in mind.

${ }^{5}$ It is said that one approach is (culture) "emic" when presents a description of the behaviour in terms of culture and, is (culture) "etic" when it comes to a description of behaviours that can be applied to other cultures so compared. These terms, with Greek roots, were introduced in 1954 by the sociologist and linguist Kenneth Lee Pike, who argued that the tools developed for describing linguistic behaviours could be adapted to the description of any human and social behaviour. Both terms are from linguistics and are related to the branches of phonology and phonetics.
} 
collective common and fundamental problems that are included in 4 of the 6 dimensions of the actual model and recalling that dimensions are only social constructs(see Wursten, 2019).

Some people, even social scientists, think that Geert Hofstede's model, because it focuses on differences between cultures, is incompatible with evolutionary psychology, which focuses on universal aspects of human nature, but I don't think that is the case, quite the contrary. Looking at the four original dimensions he identified, we find that, at bottom, they are like four hypotheses about four adaptive anthropological and sociological mechanisms, because they are the collective response to the same four universal human problems: (i) how do we deal with inequality of power, how do we accept it and how much do we expect it (ii) how do we resolve the fundamental human conflict, that is, the problem of I or We, Us or Them and the dependence on others? (iii) how do we position ourselves socially, do we prefer competition or cooperation, be the best or do the best? and, finally, being aware of the inevitability of death (and taxes), (iv) how do we deal with uncertainty and the unknown?

I believe that these four collective and adaptive mechanisms (aka culture), are a coevolutionary response to the resolution of the fundamental problems of the groups, and as a result of human societies. In fact, in my view, they are in the social genesis of our great tribes (aka nations). What Hofstede's work identified were the collective patterns of these group adaptive mechanisms. And in science it should be like he did. First the patterns are discovered, then the explanations are sought.

Geert Hofstede defines culture as "a collective program of the human mind" because it is partly shared with people who live in the same social environment, which was learned. So, in a way, culture consists of the unwritten rules of the social game. He had originally identified four dimensions of national culture ${ }^{6}$. These four dimensions are linked to four evolutionary and crucial problems of all human societies, which are: 1) Dealing with inequality involving its emotional acceptance would not be possible without coordination and human organization; 2) The dependence of others, or the dilemma of "I" versus "we" and "us" versus "them"; 3) The division of labour and of emotional roles associated with the male and the female gender and, 4) thee problem of dealing with the unknown, uncertainty and the consciousness of death.

These four collective problems are what we consider "social human universals", and how they are resolved are the basis of variation and differentiation of collective beliefs and practices that are liable to be compared and even measured. Table 1 summarizes those that I consider to be the fundamental cross-cultural problems of human societies and their underlying adaptive dilemmas.

Table 1. Summary of 4 collective problems common to all human societies on which the diversity and cultural variation evolved

Basic Human Problems

Underlying Dilemmas

Need for collective coordination

Emotional acceptance of inequality;
Differentiation
Division of Labour; Power Differences; Who
Following?

1) Power Distance (PDI), which indicates the extent to which less powerful members of a society accept that power is distributed unequally;2) Individualism versus Collectivism (IDV), which indicates the level at which individuals look after themselves or their immediate families, or instead consider themselves a part of "larger groups";3) Masculinity versus Femininity (MAS), which is not about gender, but rather about dominant values expressed: achievement, performance, status in masculine societies, cooperation, people-orientation, and consensus for the feminine societies; and 4) Uncertainty Avoidance (UAI), which indicates the extent to which people feel threatened by uncertainty, the unknown, ambiguity, and unpredictability and try to avoid these situations. 
Dependency of others

Psychology and role models associated with the Bio class (Gender/Males/Females/Child/Adult)

Dealing with death, the unknown and uncertainty
I versus We/We versus They; Social Tribal

Instinct

How Signalize the Sensitivity of belonging

Division of activities and emotions associated

with male/female/role, Competition vs.

Cooperation

Social and sexual selection; Bio classes

Need for control uncertainty and reduce anxiety

resulting from the consciousness of death and of the unknown

Source: Author's compilation based on Hofstede's $(1980,2001)$ and Hofstede et al.'s (2010) approach.

In summary, the main ideas hereabout culture and culture differences are:

- Human culture, in its multiple manifestations, is unfolded as a biological adaptive response (a bottom-up process) and as a set of persistent survival strategies, determined by evolution, ecology where developed and evolved, and psychological mechanisms involved in the evolutionary human nature.

- What today creates the cultures of Nations echoes a central tendency in every society, that is, a pattern of stable and persistent collective responses. However, culture characteristics are not some kinds of binary (all-or-nothing) thing that countries possess or do not possess. Dimensions are understood here as a spectrum (from 0 to 100).

- The different cultures are an "emergent" phenomenon living from the individuals and their EPM, but culture is more than a sum of individuals. Culture is a collective fact.

- Culture as an "information system" allows us to solve problems of collective coordination, maintain cohesion, survival, and the reproduction of society, replicating itself horizontally and vertically moved to the following generations.

- Human cultures, in their collective variations, help us maintain the evolutionary algorithm through diversity/variation, retention/selection and transmission of information and, thus, solve the fundamental existential problems replicating and perpetuating itself.

It seems reasonable to accept the idea that human culture variations can be the equivalent of the EPM. This means that cultural values or collective preferences are the equivalent of "anthropological evolutionary mechanisms" variations. Those preferences (power distance, individualism vs collectivism, masculinity vs femininity and uncertainty avoidance) allowed (and still allow) human societies to solve specific collective problems concerning their adaptation, survival and reproduction.

\section{Conclusion}

Probably, there is no opposition between the evolutionary theory and cultural differences or cultural diversity. In this perspective, all cultures have evolved with common problems to solve. Behind the different ways in which they solved (and continue to solve) these problems, there is a specific and common rational that only the history of the peoples can help clarify. However, such as "correlation does not imply causation", also the rational does not mean the "best choice" or the best results. It just means that there is a way of collective thinking, feeling and acting that has allowed somehow to solve these problems and that is why those options remain (Hagen \& Hammerstein, 2006, p. 341-343). Probably, it is because our brain is still trapped in the "stone age" that many collective behaviours probably do not already correspond adequately to the fast changes in the environment that have occurred and still occur. Our environment has changed faster than our brains 
Actuality, there is, apparently, a process of "downward causation", in the sense that national cultures are collective facts and mental programs outside the individuals and influence them from top to bottom. Nevertheless, human cultures have first emerged from an "upward causation" process (bottom-up), based simultaneously in regularities of human behaviours in all groups and as a result of our common EPM and the same existential problems that give rise to what scientists call "cultural dimensions" and are only social constructs.

\section{References}

Alexander, R. (1979). Darwinism and human affairs. Seattle: University of Washington.

Barkow, J. (2005). Darwin, sex, and prestige. Princeton: Princeton University Press.

Barkow, J., Cosmides, L., \& Tooby, J. (1992). The adapted mind: Evolutionary psychology and the generation of culture. New York: Oxford University Press.

Brown, D. (1991). Human Universals. Boston, Mass: McGraw-Hill.

Dawkins, R. (1976). The selfish gene. New York: Free Press.

Hagen, E. H., \& Hammerstein, P. (2006). Game theory and human evolution: A critique of some recent interpretations of experimental games. Theoretical Population Biology, 69, 339-348. http://dx.doi.org/10.1016/j.tpb.2005.09.005.

Hofstede, G. (1980). Culture's consequences: International differences in work-related values. Beverly Hills, CA: Sage publishers.

Hofstede, G. (2001). Culture and organizations. Comparing values, behaviours, institutions, and organizations across nations. Thousand Oaks, CA: Sage Publications.

Hofstede, G., Hofstede, G. J., \& Minkov, M. (2010). Cultures and organizations. Software of the mind. Intercultural cooperation and its importance for survival. London: McGraw Hill.

Kluckhohn, F., \& Strodbeck, F. (1961). Variations in value orientations. Westport: Greenwood.

Mayr, E. (1974). Behavior programs and evolutionary strategies. American Scientist, 62, 650659.

Messoudi, A. (2011). Cultural evolution: how Darwinian theory can explain human culture and synthesize the social sciences. Chicago, Ill.: University of Chicago Press.

Nesse, R. (2019). Good reasons for bad feelings. UK: Penguin Books.

Richerson, P., \& Boyd, R. (2006). Not by genes alone: How culture transformed human evolution. Chicago: Chicago University Press.

Tooby, J., Cosmides, L., \& Price, M. E. (2006). Cognitive adaptations for n-person exchange: The evolutionary roots of organizational behaviour. Managerial and Decision Economics, 27, 103-129. https://doi.org/10.1002/mde.1287.

Van Vugt, M. (2008, June 11). Follow me: The origins of leadership. New Scientist. https://www.newscientist.com/article/mg19826601-900-follow-me-the-origins-ofleadership/

Van Vugt, M. M., King, A., \& Johnson, D. (2009). The origins and evolution of leadership. Current Biology, 19, R911-R916. https://doi.org/10.1016/j.cub.2009.07.027.

Van Vugt, M., \& Ahuja, A. (2010). Selected: Why some people lead, why others follow, and why it matters. London: Profile Books.

Van Vugt, M., Johnson, D., Kaiser, R., \& O'Gorman, R. (2008). Evolution and the social psychology of leadership: The mismatch hypothesis. In D. Hoyt, D. Forsyth, \& A. Goethals (Eds.), The social psychology of leadership. London: Praeger.

Vieira, A. (2015). «Origem e evolução da linguagem: dados e hipóteses» in O Homem Origem e Evolução. Lisboa: Edição Glaciar 
Wursten, H. (2019). The 7 mental images of national culture: Leading and managing in a globalized world. Hofstede Insights. Amazon Books. 